\title{
Development of Genetic Algorithm (GA) Based Optimized PID Controller for Stability Analysis of DC-DC Buck Converter
}

\author{
Mirza Muntasir Nishat, Fahim Faisal, Anik Jawad Evan, Md. Moshiour Rahaman, \\ Md. Sadman Sifat, H. M. Fazle Rabbi \\ Department of Electrical and Electronic Engineering, Islamic University of Technology, Dhaka, Bangladesh \\ Email: mirzamuntasir@iut-dhaka.edu
}

How to cite this paper: Nishat, M.M., Faisal, F., Evan, A.J., Rahaman, Md.M., Sifat, Md.S. and Rabbi, H.M.F. (2020) Development of Genetic Algorithm (GA) Based Optimized PID Controller for Stability Analysis of DC-DC Buck Converter. Journal of Power and Energy Engineering, 8, 8-19. https://doi.org/10.4236/jpee.2020.89002

Received: June 28, 2020

Accepted: September 8, 2020

Published: September 11, 2020

Copyright $\odot 2020$ by author(s) and Scientific Research Publishing Inc. This work is licensed under the Creative Commons Attribution International License (CC BY 4.0).

http://creativecommons.org/licenses/by/4.0/

\begin{abstract}
This paper delineates a conventional buck converter controlled by optimized PID controller where Genetic Algorithm (GA) is employed with a view to enhancing the performance by analyzing the performance parameters. Genetic Algorithm is a probabilistic search algorithm which is substantially used as an optimization technique in power electronics. A bunch of modifications have already been introduced to enhance the performance depending upon the applications. However, in this paper, modified genetic algorithm has been used in order to tune the key parameters in the converter. Hence, an analysis is carried out where the performance of the converter is illustrated in terms of rise time, settling time and percentage of overshoot by deploying GA based PID controller and the overall comparative study is presented. Responses of the overall system are accumulated through rigorous simulation in MATLAB environment.
\end{abstract}

\section{Keywords}

Genetic Algorithm, Optimization, PID Controller, Converter: State Space Average Method

\section{Introduction}

As human civilization is stepping into $22^{\text {nd }}$ century the researchers are more enthusiastic to build robust and electrically stable systems. In this regard, DC-DC converters [1] are top of the list as it is utilized in numerous equipment like Motor drivers, Robotic hands [2], and Smart Home systems [3] and so on. Among various DC-DC converters, Buck, Boost, Buck-Boost, SEPIC and Cuk 
[4] [5] [6] [7] [8] converters are the most commonly used converters. Generally, Boost converters increase the output voltages according to the demand on load side and duty cycle. Both Buck-Boost and Cuk converters can increase and decrease the output voltage. In case of the boost converters researchers have found that the efficiency is very poor for high gain and it fails big time when it comes in case of controlling it. On the other hand, for Buck-Boost converters, the charging current of output capacitor is discontinuous and the controlling mechanism is also troublesome [9] [10].

Therefore, Buck converters significantly overcome the above problems and can be controlled by numerous controlling methods. Among various methods, PID (Proportional, Integral, and Differential) controller [11] [12] is the most widely employed controller. But tuning these parameters and obtaining the optimized values are the major challenges for control engineers. Therefore, different algorithms i.e. inpaint [13] [14], spectroscopy [15], annealing are deployed in order to achieve the optimized values of the controller. For this, Genetic Algorithm proves to be a handy tool as it utilizes the concept of probabilistic search algorithm. In each generation, the fitness of the whole population is evaluated, multiple individuals are stochastically selected from the current population (based on their fitness) and modified (mutated or recombined) to form a new population. This process is repeated until the conditions are satisfied [16] [17] [18] [19] [20].

In Section 2, the circuit of conventional Buck converter is studied and State Space Modeling of the converter is illustrated. The elaborate discussion on implementation of Genetic Algorithm is depicted in Section 3 where overviews, objective function of the algorithm and design of the GA based PID Controller are stated. Finally, the results of the simulation and stability analysis of the system are shown and discussed in Section 4. Lastly, the overall comparative analysis is presented. All the simulations are carried out in MATLAB.

\section{State Space Average Method}

The conventional DC-DC Buck Converter comprises of inductor (L), capacitor $(\mathrm{C})$, diode $\mathrm{D}$, switch $(\mathrm{S})$ and load resistance $(\mathrm{R})$ which is shown in Figure 1.

When the switch $\mathrm{S}$ is $\mathrm{ON}$, the diode becomes open and capacitor (C) discharges through load resistance (R). When the switch (S) is OFF, the diode is closed and current $i_{L}$ passes through the capacitor $(\mathrm{C})$ and load resistance (R). For mathematical modeling of DC-DC Buck Converter, State Space Modeling [22] is employed so that the system can be illustrated by first order differential equations followed by matrix representation.

The system matrix is denoted as A, B, C and D; $u$ and $y$ are referred as input and output respectively. The state variable is indicated as $x$ and $x^{\prime}$ is the derivative of state variables. Here, current $i_{L}$ and voltage $V_{C}$ are system variables which are mapped as $i_{L}=x_{1}$ and $v_{C}=x_{2}$.

$$
x^{\prime}=A x+B u
$$




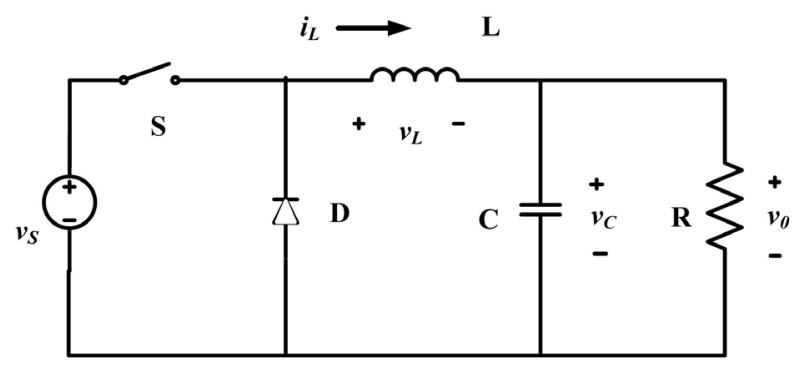

Figure 1. Circuit diagram of conventional buck converter [21].

$$
y=C x+D u
$$

The circuit diagrams for ON and OFF condition of the switch (S) are shown in Figure 2(a) and Figure 2(b) respectively. The equations derived for these two conditions are presented as follows.

When $\mathrm{S}$ is $\mathrm{ON}$ :

$$
\begin{gathered}
v_{S}=L \frac{\mathrm{d} i_{L}}{\mathrm{~d} t}+v_{C} \\
i_{L}=C \frac{\mathrm{d} v_{C}}{\mathrm{~d} t}+\frac{v_{C}}{R} \\
x_{1}^{\prime}=-\frac{1}{L} x_{2}+\frac{1}{L} v_{S} \\
\left(\begin{array}{l}
x_{1}^{\prime} \\
x_{2}^{\prime}
\end{array}\right)=\left(\begin{array}{cc}
C & x_{1}-\frac{1}{R C} x_{2} \\
0 & -\frac{1}{L} \\
\frac{1}{C} & -\frac{1}{R C}
\end{array}\right)\left(\begin{array}{l}
x_{1} \\
x_{2}
\end{array}\right)+\left(\begin{array}{l}
\frac{1}{L} \\
0
\end{array}\right) v_{S}
\end{gathered}
$$

When $\mathrm{S}$ is OFF:

$$
\begin{gathered}
0=v_{C}+L \frac{\mathrm{d} i_{L}}{\mathrm{~d} t} \\
i_{L}=C \frac{\mathrm{d} v_{C}}{\mathrm{~d} t}+\frac{v_{C}}{R} \\
x_{1}^{\prime}=-\frac{1}{L} x_{2} \\
x_{2}^{\prime}=-\frac{1}{C} x_{1}-\frac{1}{R C} x_{2} \\
\left(\begin{array}{l}
x_{1}^{\prime} \\
x_{2}^{\prime}
\end{array}\right)=\left(\begin{array}{cc}
0 & -\frac{1}{L} \\
\frac{1}{C} & -\frac{1}{R C}
\end{array}\right)\left(\begin{array}{l}
x_{1} \\
x_{2}
\end{array}\right)+\left(\begin{array}{l}
0 \\
0
\end{array}\right) v_{S}
\end{gathered}
$$

The average of the state space model is illustrated below where switching duty cycle $(d)$ is taken into consideration.

$$
A^{\prime}=A_{\mathrm{ON}} d+A_{\mathrm{OFF}}(1-d)
$$




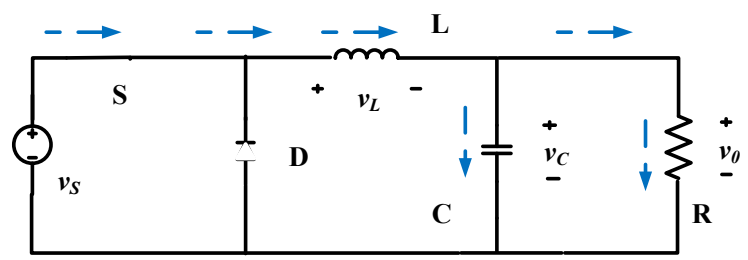

(a)

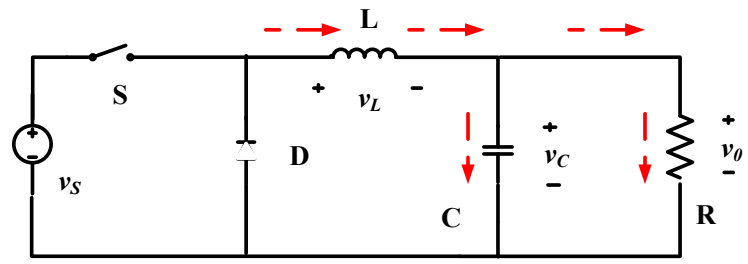

(b)

Figure 2. Circuits of buck converter at switch, S (a) ON and (b) OFF.

$$
\begin{gathered}
A^{\prime}=\left(\begin{array}{cc}
0 & -\frac{1}{L} \\
\frac{1}{C} & -\frac{1}{R C}
\end{array}\right) d+\left(\begin{array}{cc}
0 & -\frac{1}{L} \\
\frac{1}{C} & -\frac{1}{R C}
\end{array}\right)(1-d)=\left(\begin{array}{cc}
0 & -\frac{1}{L} \\
\frac{1}{C} & -\frac{1}{R C}
\end{array}\right) \\
B^{\prime}=B_{\mathrm{ON}} d+B_{\mathrm{OFF}}(1-d) \\
B^{\prime}=\left(\begin{array}{l}
\frac{1}{L} \\
0
\end{array}\right) d+\left(\begin{array}{l}
0 \\
0
\end{array}\right)(1-d)=\left(\begin{array}{l}
\frac{d}{L} \\
0
\end{array}\right)
\end{gathered}
$$

Hence, the completed buck converter state space model is shown below:

$$
\left(\begin{array}{l}
x_{1}^{\prime} \\
x_{2}^{\prime}
\end{array}\right)=\left(\begin{array}{cc}
0 & -\frac{1}{L} \\
\frac{1}{C} & -\frac{1}{R C}
\end{array}\right)\left(\begin{array}{l}
x_{1} \\
x_{2}
\end{array}\right)+\left(\begin{array}{l}
\frac{d}{L} \\
0
\end{array}\right) v_{S}
$$

\section{Implementation of Genetic Algorithm}

Genetic algorithm (GA) is the method for solving both constrained and unconstrained optimization problems based on natural selection process that mimics biological evolution. The algorithm repeatedly modifies a population of individual solutions. At each step, the genetic algorithm randomly selects individuals from the current population and uses them as parents to produce the children for the next generation [23] [24] [25]. In genetic algorithm, a fitness function is taken into account to check how close a given design solution is in order to achieve the set value. Chromosome or genotype is a set of parameters which defines a proposed solution to the problem that the algorithm is trying to solve. The set of all solutions is known as the population.

However, crossover is a genetic operator used to vary the programming of a chromosome or chromosomes from one generation to the next. It is analogous to reproduction and biological crossover, upon which genetic algorithms are based on. Mutation is a used to maintain genetic diversity from one generation 
of a population to the next generations. It alters one or more gene values in a chromosome from its initial state. Moreover, Selection is the stage of a genetic algorithm in which individual genomes are chosen from a population for later breeding. The flow chart for the algorithm is shown in Figure 3.

In order to implement Genetic Algorithm, objective functions are chosen to evaluate the fitness of the chromosome [27]. In this paper, four performance indices are selected to minimize the error which defined as Integral of Absolute Magnitude of Error (IAE), Integral of Time multiplied by Absolute Error (ITAE), Integral of Squared Error (ISE) and Integral of Time multiplied by Squared Error (ITSE).The corresponding equations of the performance indices are as follows:

$$
\begin{aligned}
\text { IAE } & =\int_{0}^{\tau}|e(t)| \mathrm{d} t \\
\text { ITAE } & =\int_{0}^{\tau} t|e(t)| \mathrm{d} t
\end{aligned}
$$

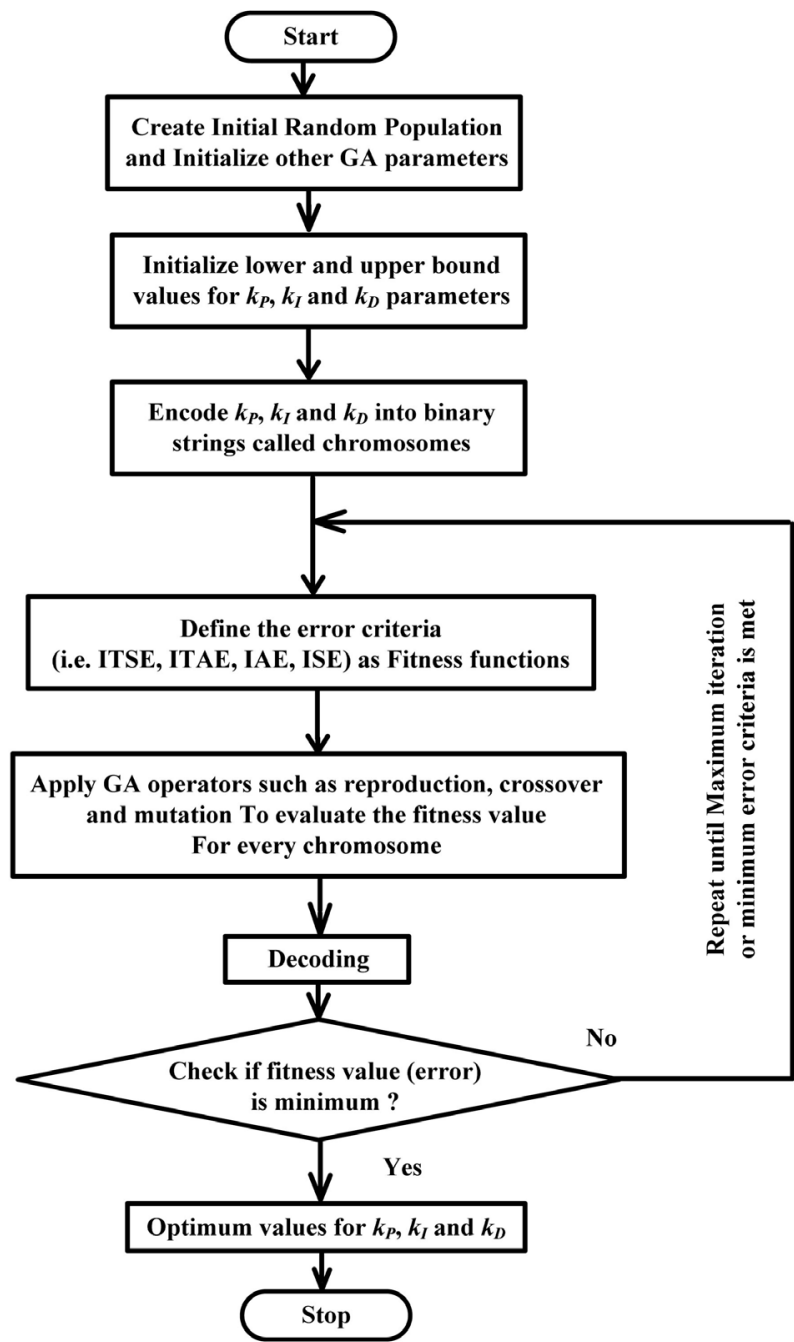

Figure 3. Flow chart of genetic algorithm [26]. 


$$
\begin{gathered}
\text { ISE }=\int_{0}^{\tau} e(t)^{2} \mathrm{~d} t \\
\text { ITSE }=\int_{0}^{\tau} t e(t)^{2} \mathrm{~d} t
\end{gathered}
$$

The basic block diagram of the system is shown in Figure 4. In order to tune the parameters of PID controller through genetic algorithm, the $k_{P}, k_{I}$ and $k_{D}$ are taken and the chromosome is formed. The main objective of the study is to minimize the error between the input and the plant's output.

\section{Simulation Results and Stability Analysis}

Model order reduction technique is carried out in MATLAB so that the higher order transfer function obtained from the state space modeling can be converted into a simpler form. Table 1 presents the converter parameters that are used for mathematical calculation and simulation of the stability of the Buck converter.

Firstly, Buck converter for the conventional PID controller is employed and the response is taken to observe the stability of the system which is shown in Figure 5.

So, from Figure 5, gain values of $k_{B}, k_{I}$ and $k_{D}$ are accumulated, tabulated and shown in Table 3. After that, Genetic Algorithm (GA) based PID controller is deployed in the system to determine more optimum values of $k_{P}, k_{I}$ and $k_{D}$. The parameters are listed in Table 2.

After rigorous simulation in MATLAB, the values of $k_{P}, k_{I}$ and $k_{D}$ are obtained for all of the four performance indices of GA based PID controller which is evident in Table 3 along with the conventional PID controller.

Step responses for IAE, ITAE, ISE and ITSE and performance parameters are illustrated in Figures 6-9 respectively.

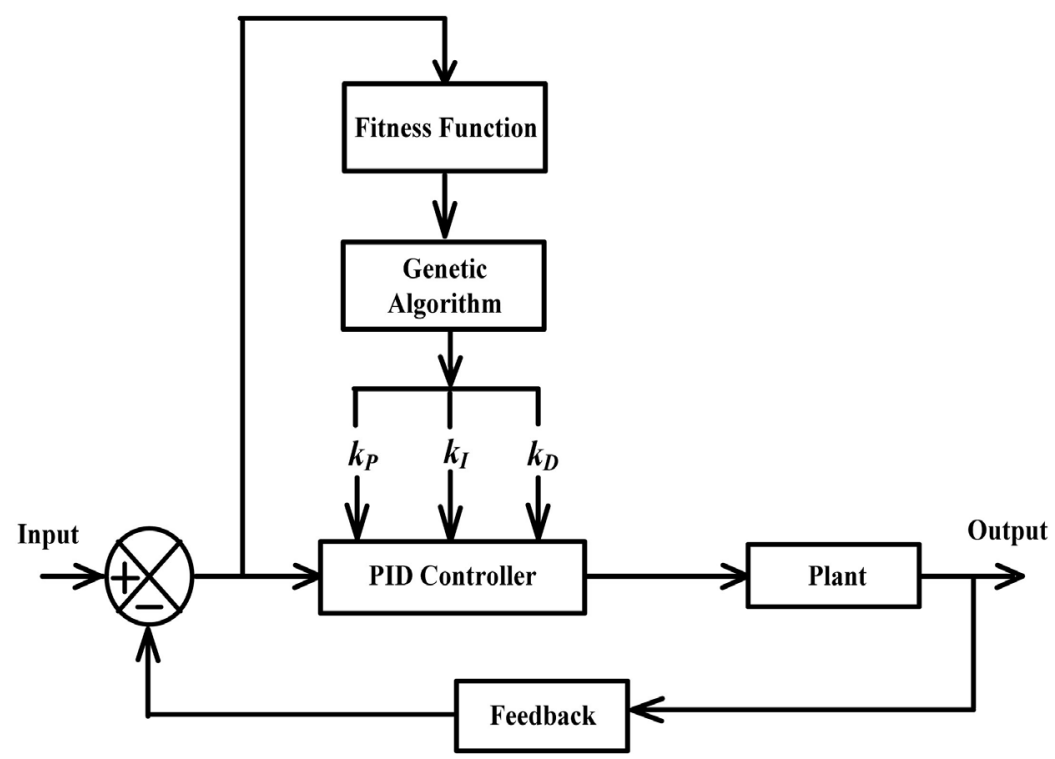

Figure 4. Basic block diagram of GA based PID controller [28]. 


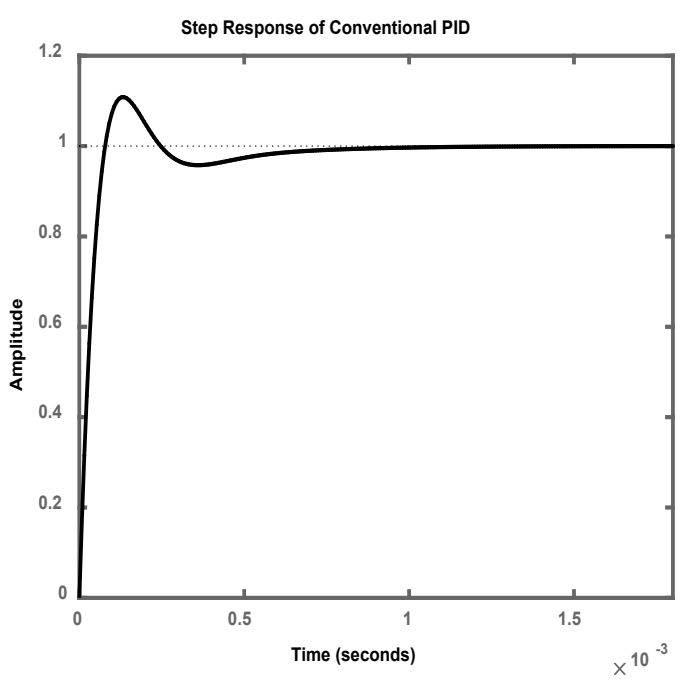

Figure 5. Step response of conventional PID controller.

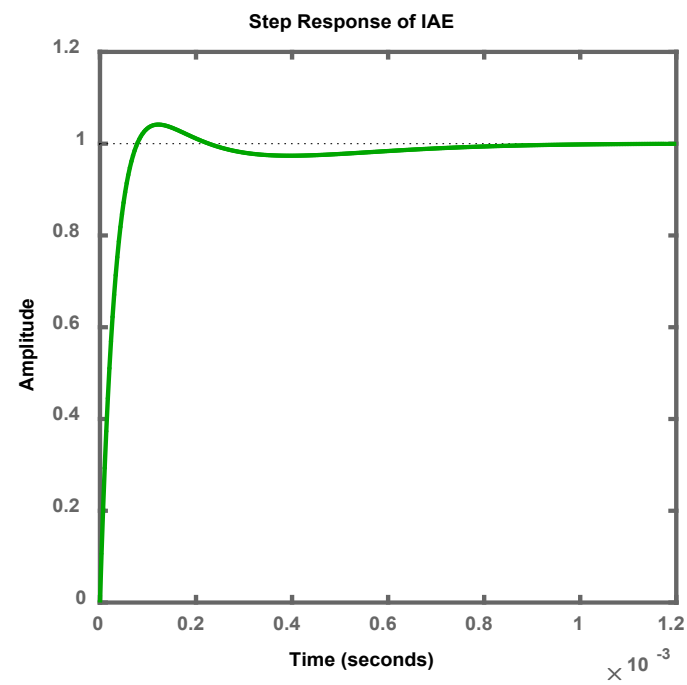

Figure 6. Step response of IAE.

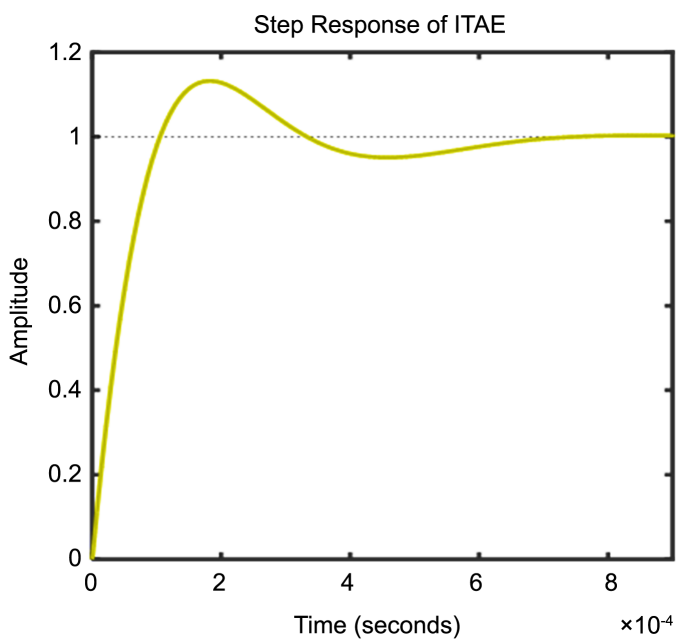

Figure 7. Step response of ITAE. 


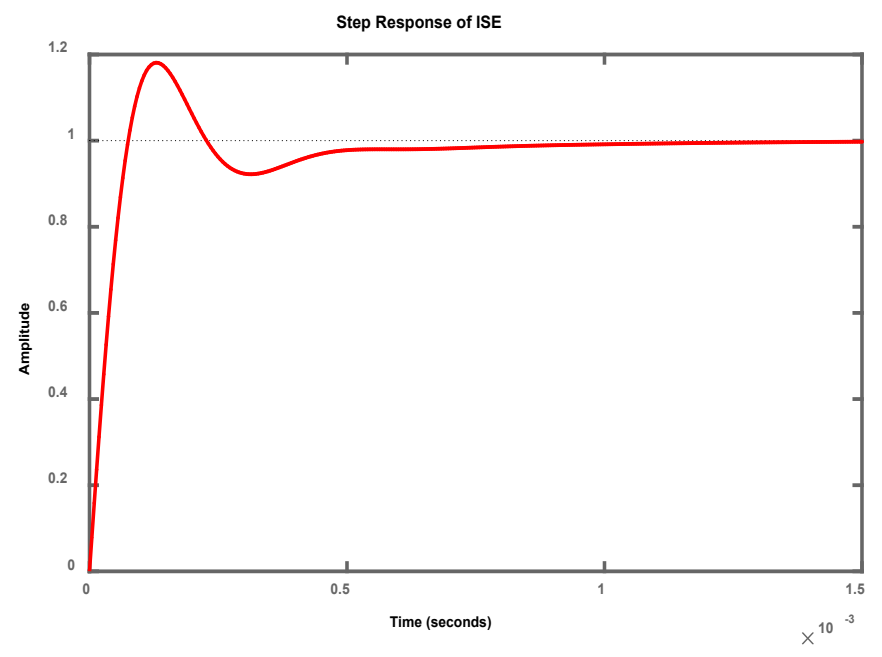

Figure 8. Step response of ISE.

Table 1. Parameters of the buck converter.

\begin{tabular}{cc}
\hline Name of the Components & Values \\
\hline Input Voltage, $v s$ & $12 \mathrm{~V}$ \\
Output Voltage, $v_{o}$ & $5.574 \mathrm{~V}$ \\
Capacitor, C & $200 \mu \mathrm{F}$ \\
Inductor, L & $145 \mu \mathrm{H}$ \\
Output Resistor, R & $1 \Omega$
\end{tabular}

Table 2. Parameters of genetic algorithm.

\begin{tabular}{cc}
\hline Name of the Parameters & Values \\
\hline Population & 50 \\
Fitness Scaling & Rank \\
Selection & Stochastic Uniform \\
Mutation & 0.1 \\
Crossover & 0.8 \\
\hline
\end{tabular}

Table 3. Gain values for both conventional and GA Based PID controller.

\begin{tabular}{cccccc}
\hline \multirow{2}{*}{ Gain } & \multirow{2}{*}{ Conventional PID } & \multicolumn{4}{c}{ GA-PID } \\
\cline { 3 - 6 } & & IAE & ITAE & ISE & ITSE \\
\hline $\boldsymbol{k}_{P}$ & 19.1228 & 18.85 & 11.38 & 22.046 & 14.268 \\
$\boldsymbol{k}_{\boldsymbol{I}}$ & $60,517.0162$ & $64,869.2$ & 59,637 & $48,926.2$ & $45,350.9$ \\
$\boldsymbol{k}_{\boldsymbol{D}}$ & 0.00135 & 0.002 & 0.000943 & 0.001 & 0.001 \\
\hline
\end{tabular}

The performance parameters like Percentage of Overshoot (\%OS), Rise Time (Tr), Settling Time (Ts) and Peak Amplitude are tabulated for both conventional and GA based PID Controller which is presented in Table 4.

It is evident from the results that IAE portrays better results than other controllers. The overall comparative analysis of the step responses is illustrated in Figure 10. 


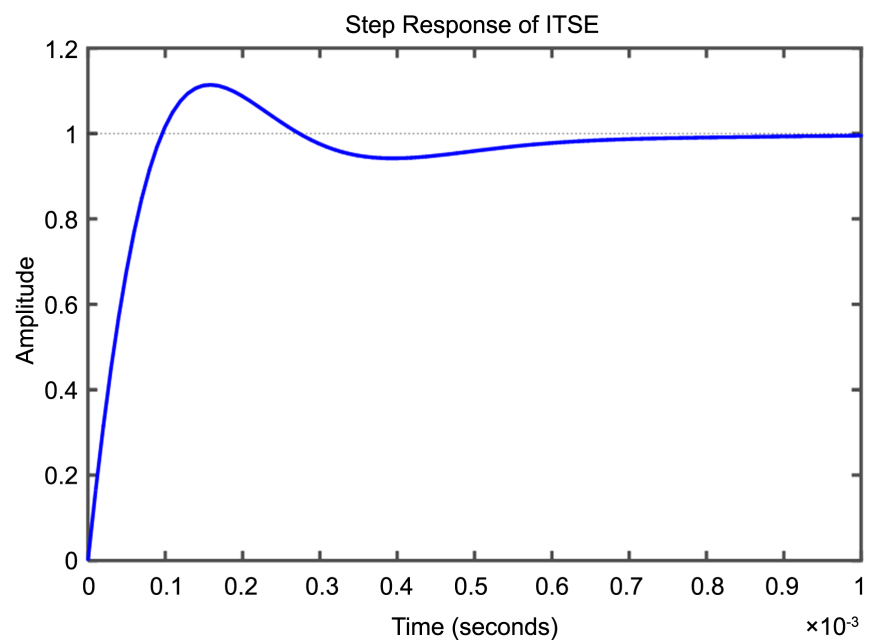

Figure 9. Step response of ITSE.

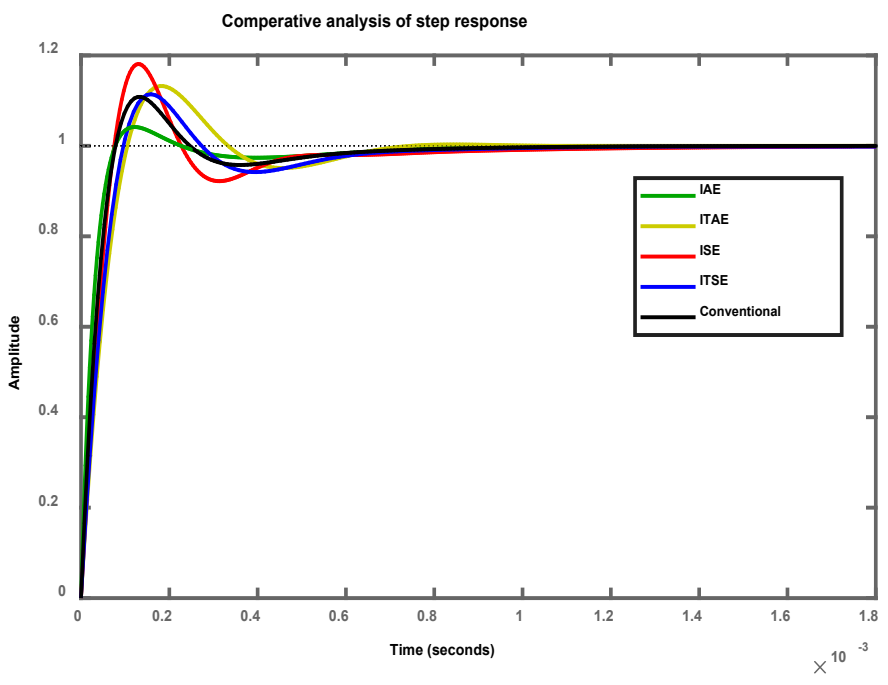

Figure 10. Comparative analyses of step responses.

Table 4. Performance parameters for both conventional and GA based PID controller.

\begin{tabular}{cccccc}
\hline \multirow{2}{*}{$\begin{array}{c}\text { Performance } \\
\text { Parameters }\end{array}$} & \multirow{2}{*}{$\begin{array}{c}\text { Conventional } \\
\text { PID }\end{array}$} & \multicolumn{4}{c}{ GA-PID } \\
\cline { 3 - 6 } & & IAE & ITAE & ISE & ITSE \\
\hline \%OS & 10.8 & 4.17 & 13.2 & 18.1 & 11.4 \\
$T R$ & 0.0000573 & 0.0000504 & 0.0000784 & 0.0000575 & 0.0000712 \\
$T S$ & 0.000552 & 0.000538 & 0.000614 & 0.000634 & 0.000616 \\
Peak Amplitude & 1.11 & 1.04 & 1.13 & 1.18 & 1.11 \\
\hline
\end{tabular}

\section{Conclusion}

In this paper, an investigative study on stability analysis of closed loop Buck converter is brought into action by GA based PID controller. It is observed that IAE depicts more optimized results in terms of overshoot $(4.17 \%)$, rise time (0.0000504 s), settling time (0.000538 s) than other performance indices. The 
overall comparative analysis of step response provides an idea of the stability of the converter. Hence, it can be concluded that GA based PID controller is more convenient than other tuning methods for Buck converter. Thus, more efficient and stable equipment can be designed by utilizing this modern algorithm based technique.

\section{Conflicts of Interest}

The authors declare no conflicts of interest regarding the publication of this paper.

\section{References}

[1] Nishat, M.M., Faisal, F. and Hoque, M.A. (2019) Modeling and Stability Analysis of a DC-DC SEPIC Converter by Employing Optimized PID Controller Using Genetic Algorithm. International Journal of Electrical \& Computer Sciences, 19, 1-7.

[2] Murray, R.M. (1994) A Mathematical Introduction to Robotic Manipulation. CRC Press, Boca Raton, FL.

[3] Zhou, B., et al. (2016) Smart Home Energy Management Systems: Concept, Configurations, and Scheduling Strategies. Renewable and Sustainable Energy Reviews, 61, 30-40. https://doi.org/10.1016/j.rser.2016.03.047

[4] Poorali, B., Adib, E. and Farzanehfard, H. (2017) Soft-Switching DC-DC Cuk Converter Operating in Discontinuous-Capacitor-Voltage Mode. IET Power Electronics, 10, 1-18.

[5] Zhang, C., Wang, J., Li, S., Wu, B. and Qian, C. (2015) Robust Control for PWM-Based DC-DC Buck Power Converters with Uncertainty via Sampled-Data Output Feedback. IEEE Transactions on Power Electronics, 30, 504-515. https://doi.org/10.1109/TPEL.2014.2299759

[6] Rashid, M.B., Oninda, M.A.M., Faisal, F., Nishat, M.M., Sarowar, G. and Hoque, M.A. (2018) A Novel Topology of Single-Phase AC-DC Integrated Boost-SEPIC (IBS) Converter Using Common Part Sharing Method (CPSM) for High Step-Up Applications. Journal of Power and Energy Engineering, 6, 38-47. https://doi.org/10.4236/jpee.2018.66003

[7] Ali, N., Hagh, M.T., Sharifian, M.B.B. and Danyali, S. (2015) A Nonisolated Multiinput Multioutput DC-DC Boost Converter for Electric Vehicle Applications. IEEE Transactions on Power Electronics, 30, 1818-1835. https://doi.org/10.1109/TPEL.2014.2325830

[8] Nishat, M.M., Faisal, F., Oninda, M.A.M. and Hoque, M.A. (2018) Modeling, Simulation and Performance Analysis of SEPIC Converter Using Hysteresis Current Control and PI Control Method. 2018 International Conference on Innovations in Science, Engineering and Technology (ICISET), Chittagong, 27-28 October 2018, 7-12.

[9] Nishat, M.M., Faisal, F., Rahman, M. and Hoque, M.A. (2019) Modeling and Design of a Fuzzy Logic Based PID Controller for DC Motor Speed Control in Different Loading Condition for Enhanced Performance. 2019 1st International Conference on Advances in Science, Engineering and Robotics Technology (ICASERT), Dhaka, 3-5 May 2019, 1-6. https://doi.org/10.1109/ICASERT.2019.8934559

[10] Nishat, M.M., Faisal, F., Hoque, M.A., Evan, A.J., Rahaman, M.M., Sifat, M.S. and Fazle Rabbi, H.M. (2019) Stability Analysis and Optimization of Simulated Annealing (SA) Algorithm Based PID Controller for DC-DC SEPIC Converter. Interna- 
tional Journal of Computer Science and Network Security, 19, 1-8.

[11] Kumar, S., Shekhar, V., Shyam, Y. and Nagar, K. (2017) Optimization of Fractional Order PID Controller Using Grey Wolf Optimizer. Journal of Control, Automation and Electrical Systems, 28, 314-322. https://doi.org/10.1007/s40313-017-0305-3

[12] Kadu, C.B. and Patil, C.Y. (2016) Design and Implementation of Stable PID Controller for Interacting Level. Procedia Computer Science, 79, 737-746. https://doi.org/10.1016/j.procs.2016.03.097

[13] Farazi, M.R., Faisal, F., Zaman, Z. and Farhan, S. (2016) Inpainting Multiple Sclerosis Lesions for improving Registration Performancewith Brain Atlas. 2016 International Conference on Medical Engineering, Health Informatics and Technology (MediTec), Dhaka, 17-18 December 2016, 1-6. https://doi.org/10.1109/MEDITEC.2016.7835363

[14] Faisal, F. and Nishat, M.M. (2019) An Investigation for Enhancing Registration Performance with Brain Atlas by Novel Image Inpainting Technique Using Diceand Jaccard Score on Multiple Sclerosis (MS) Tissue. Biomedical and Pharmacology Journal, 12, 1249-1262. https://doi.org/10.13005/bpj/1754

[15] Nishat, M.M. and Faisal, F. (2019) An Investigation of Spectroscopic Characterization on Biological Tissue. 2018 4th International Conference on Electrical Engineering and Information \& Communication Technology, Dhaka, 13-15 September 2018, 290-295. https://doi.org/10.1109/CEEICT.2018.8628081

[16] Mantri, G. and Kulkarni, N.R. (2013) Design and Optimization of PID Controller Using Genetic Algorithm. International Journal of Engineering Research and Technology, 6, 926-930. https://doi.org/10.15623/ijret.2013.0206002

[17] Vladu, E.E. and Dragomir, T.L. (2004) Controller Tuning Using Genetic Algorithms. International Journal of Research in Engineering and Technology, 1-10.

[18] Shubham, P., Meenakshi, K. and Rajeev, G. (2014) Optimal Tuning of PID Controller Using Genetic Algorithm and Swarm Techniques. International Journal of Electronic and Electrical Engineering, 7, 189-194.

[19] Roeva, O., Fidanova, S. and Paprzycki, M. (2013) Influence of the Population Size on The Genetic Algorithm Performance in Case of Cultivation Process Modelling. Recent Advances in Computational Optimization, 580, 107-120. https://doi.org/10.1007/978-3-319-12631-9 7

[20] Jaen-Cuellar, A.Y., de Romero-Troncoso, J.R., Morales-Velazquez, L. and Osornio-Rios, R.A (2013) PID-Controller Tuning Optimization with Genetic Algorithms in Servo Systems. International Journal of Advanced Robotic Systems, 10, 324. https://doi.org/10.5772/56697

[21] Tan, R.H.G. and Hoo, L.Y.H (2015) DC-DC Converter Modeling and Simulation Using State Space Approach. 2015 IEEE Conference on Energy Conversion, Johor Bahru, 19-20 October 2015, 42-47. https://doi.org/10.1109/CENCON.2015.7409511

[22] Faisal, F., Nishat, M.M. and Mia, Md.R. (2019) An Investigation on DC Motor Braking System by Implementing Electromagnetic Relay and Timer. 2019 International Conference on Electrical, Computer and Communication Engineering (ECCE), 1-6. https://doi.org/10.1109/ECACE.2019.8679225

[23] Hiassat, A., Diabat, A. and Rahwan, I. (2017) A Genetic Algorithm Approach for Location-Inventory-Routing Problem with Perishable Products. Journal of Manufacturing Systems, 42, 93-103. https://doi.org/10.1016/j.jmsy.2016.10.004

[24] Yuan, X. and Elhoseny, M. (2016) A Genetic Algorithm-Based, Dynamic Clustering Method towards Improved WSN Longevity. Journal of Network and Systems Management, 25, 21-46. https://doi.org/10.1007/s10922-016-9379-7 
[25] Ding, Y. and Fu, X. (2016) Kernel-Based Fuzzy c-Means Clustering Algorithm Based on Genetic Algorithm. Neurocomputing, 188, 233-238.

https://doi.org/10.1016/j.neucom.2015.01.106

[26] Meena, D.C. and Devanshu, A. (2017) Genetic Algorithm Tuned PID Controller for Process Control. 2017 International Conference on Inventive Systems and Control (ICISC), Coimbatore, 19-20 January 2017, 1-6. https://doi.org/10.1109/ICISC.2017.8068639

[27] Mirzal, A., Yoshii, S. and Furukawa, M. (2012) PID Parameters Optimization by Using Genetic Algorithm. arXiv preprint, arXiv:1204.0885.

[28] Nishat, M.M., Faisal, F., Hoque, Md.A., Al Musawi, S.S.S., Uddin, S.M.R., Evan, K.H., Taif-Ul-Kabir, S.M. (2019) Stability Analysis of DC-DC Boost Converter by Employing Simulated Annealing Algorithm Based Optimized PI Controller. International Conference on Control, Automation, Robotics and Vision Engineering (ICCARVE), Singapore. 